University of Wollongong

Research Online

Australian Institute for Innovative Materials -

Papers

Australian Institute for Innovative Materials

2007

Two different modes of halogen bonding in two 4-nitroimidazole derivatives

Maciej Kubicki

Adam Mickiewicz University

Pawel Wagner

University of Wollongong, pawel@uow.edu.au

Follow this and additional works at: https://ro.uow.edu.au/aiimpapers

Part of the Engineering Commons, and the Physical Sciences and Mathematics Commons

Research Online is the open access institutional repository for the University of Wollongong. For further information contact the UOW Library: research-pubs@uow.edu.au 


\title{
Two different modes of halogen bonding in two 4-nitroimidazole derivatives
}

\begin{abstract}
In the crystal structures of the two imidazole derivatives 5-chloro-1,2-dimethyl-4-nitro- $1 \mathrm{H}$-imidazole, $\mathrm{C}_{5} \mathrm{H}_{6} \mathrm{ClN}_{3} \mathrm{O}_{2}$, (I), and 2-chloro-1-methyl-4-nitro-1 $\mathrm{H}$-imidazole, $\mathrm{C}_{4} \mathrm{H}_{4} \mathrm{ClN}_{3} \mathrm{O}_{2}$, (II), $\mathrm{C}-\mathrm{Cl} . . . \mathrm{O}$ halogen bonds are the principal specific interactions responsible for the crystal packing. Two different halogen-bond modes are observed: in $(I)$, there is one very short and directional $\mathrm{C}-\mathrm{Cl}$...O contact $[\mathrm{Cl} . . .0=2.899(1) \AA]$, while in (II), the $\mathrm{C}-\mathrm{Cl}$ group approaches two different $\mathrm{O}$ atoms from two different molecules, and the contacts are longer [3.285 (2) and 3.498 (2) $\AA$ ] and less directional. In (I), relatively short C-H...O hydrogen bonds provide the secondary interactions for building the crystal structure; in (II), the $\mathrm{C}-\mathrm{H}$... $\mathrm{O}$ contacts are longer but there is a relatively short $\pi-\pi$ contact between molecules related by a centre of symmetry. The molecule of $(I)$ is almost planar, the plane of the nitro group making a dihedral angle of $6.97(7)^{\circ}$ with the mean plane of the imidazole ring. The molecule of (II) has crystallographically imposed mirror symmetry and the nitro group lies in the mirror plane.
\end{abstract}

\section{Keywords}

derivatives, modes, different, halogen, two, bonding, 4, nitroimidazole

Disciplines

Engineering | Physical Sciences and Mathematics

\section{Publication Details}

Kubicki, M. \& Wagner, P. (2007). Two different modes of halogen bonding in two 4-nitroimidazole derivatives. Acta Crystallographica Section C: Crystal Structure Communications, 63 (8), o454-0457. 
Acta Crystallographica Section C

\section{Crystal Structure}

Communications

ISSN 0108-2701

\section{Two different modes of halogen bonding in two 4-nitroimidazole derivatives}

\author{
Maciej Kubicki $^{\mathrm{a} *}$ and Paweł Wagner ${ }^{\mathrm{b}}$ \\ a Department of Chemistry, Adam Mickiewicz University, Grunwaldzka 6, 60-780 \\ Poznań, Poland, and ${ }^{\mathbf{b}}$ Nanomaterials Research Centre, and MacDiarmid Institute for \\ Advanced Materials and Nanotechnology, Massey University, Private Bag 11 222, \\ Palmerston North, New Zealand \\ Correspondence e-mail: mkubicki@amu.edu.pl
}

Received 15 June 2007

Accepted 18 June 2007

Online 5 July 2007

In the crystal structures of the two imidazole derivatives 5-chloro-1,2-dimethyl-4-nitro- $1 \mathrm{H}$-imidazole, $\mathrm{C}_{5} \mathrm{H}_{6} \mathrm{ClN}_{3} \mathrm{O}_{2}$, (I), and 2-chloro-1-methyl-4-nitro- $1 \mathrm{H}$-imidazole, $\mathrm{C}_{4} \mathrm{H}_{4} \mathrm{ClN}_{3} \mathrm{O}_{2}$, (II), $\mathrm{C}-\mathrm{Cl} \cdots \mathrm{O}$ halogen bonds are the principal specific interactions responsible for the crystal packing. Two different halogen-bond modes are observed: in (I), there is one very short and directional $\mathrm{C}-\mathrm{Cl} \cdots \mathrm{O}$ contact $[\mathrm{Cl} \cdots \mathrm{O}=$ 2.899 (1) $\AA$ ], while in (II), the $\mathrm{C}-\mathrm{Cl}$ group approaches two different $\mathrm{O}$ atoms from two different molecules, and the contacts are longer [3.285(2) and $3.498(2) \AA]$ and less directional. In (I), relatively short $\mathrm{C}-\mathrm{H} \cdots \mathrm{O}$ hydrogen bonds provide the secondary interactions for building the crystal structure; in (II), the $\mathrm{C}-\mathrm{H}$. . O contacts are longer but there is a relatively short $\pi-\pi$ contact between molecules related by a centre of symmetry. The molecule of (I) is almost planar, the plane of the nitro group making a dihedral angle of $6.97(7)^{\circ}$ with the mean plane of the imidazole ring. The molecule of (II) has crystallographically imposed mirror symmetry and the nitro group lies in the mirror plane.

\section{Comment}

Halogen atoms covalently bound to a $\mathrm{C}$ atom can take part in the determination of crystal structure (i.e. the supramolecular architecture of molecular crystals) via interactions with the electron pairs of other atoms, interactions with other halogen atoms or acceptance of weak hydrogen bonds. The attractive interactions between halogens and atoms that have lone electron pairs have been known for some time (e.g. Hassel \& Rømming, 1962; Bent, 1968; Dahl \& Hassel, 1970; Hassel, 1970). This interaction was termed halogen bonding (Dumas et al., 1983; Legon, 1998), in order to stress some geometrical correspondences with hydrogen bonding, for instance the striking tendency towards the linearity of the $\mathrm{C}-X \cdots Y$ system [for reviews, see, for example, Legon (1999) and
Metrangolo et al. (2005)]. The halogen atom acts here as a Lewis acid. Database analysis (Lommerse et al., 1996) and quantum mechanical calculations (Valerio et al., 2000) allowed the 'acidity' of halogens to be characterized as $\mathrm{I}>\mathrm{Br}>\mathrm{Cl}$, while fluorine generally does not participate in such interactions. Halogen bonds have been utilized successfully in the creation of supramolecular systems; for example, it has been shown that these interactions can create molecular tapes (Reddy, Panneerselvam et al., 1993) or a diamondoid structure (Reddy, Craig et al., 1993). They have also been used for designing molecular conductors (Imakubo et al., 1998), hostguest systems (Messina et al., 2001) and nonlinear optical crystals (George et al., 2004). Intermolecular $\mathrm{N} \cdots X$ interactions have also been found in solution (Wash et al., 1999) and in the gas phase (Legon, 1999). Quite recently, experimental electron-density studies have clearly shown the presence of an interaction path and critical points connected with $\mathrm{I} \cdots \mathrm{N}$ and $\mathrm{I} \cdots \mathrm{O}$ interactions, and the results of these studies confirmed the electrostatic nature of halogen bonds (Bianchi et al., 2003, 2004).

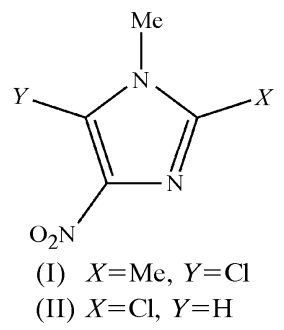

Allen et al. (1997) analyzed the halogen ... $\mathrm{O}_{\text {nitro }}$ supramolecular synthon [in the sense defined by Desiraju (1995)] using both a crystallographic database and $a b$ initio molecular orbital calculations. They found that in $46 \%$ of the crystal structures containing both $\mathrm{C}-\mathrm{NO}_{2}$ and $\mathrm{C}-X(X=\mathrm{Cl}, \mathrm{Br}$ or I $)$ fragments there are $X \cdots \mathrm{O}$ contacts shorter than the sum of the van der Waals radii plus $0.2 \AA$. Following Desiraju et al.

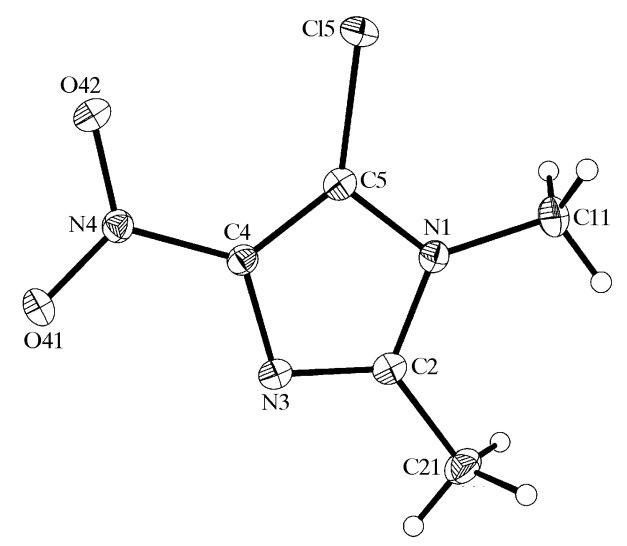

Figure 1

An anisotropic displacement ellipsoid representation of the molecule of (I), together with the atom-labelling scheme (Siemens, 1989). The ellipsoids are drawn at the $50 \%$ probability level and $\mathrm{H}$ atoms are depicted as spheres with arbitrary radii. 
(1993), three types of halogen-bond system were defined. In the first two cases, the approach of a halogen atom to a nitro group is such that both $X \cdots \mathrm{O}$ lines are trans to the $\mathrm{C}-\mathrm{N}$ bond, forming (i) a symmetrical bifurcated motif, with $X \cdots \mathrm{O} 1 \simeq X \cdots \mathrm{O} 2$, or (ii) an asymmetric motif, where one of the distances is so long that there is no interaction. Possibility (iii) is a cis approach to one of the $\mathrm{O}$ atoms. The results of this analysis show also that for chlorine there is a strong tendency to form 'monocoordinate interactions' (ii) or (iii), with only one $\mathrm{O}$ atom, rather than bifurcated contacts with both $\mathrm{O}$ atoms as in (i). This latter arrangement is typical for iodine and to some extent for bromine; such an almost symmetrical bifurcated halogen bond was found in a similar imidazole derivative, viz. 1-(4-bromophenyl)-2-methyl-4-nitroimidazole (Kubicki, 2004).

In the course of our studies of weak intermolecular interactions in the crystal structures of simple 4-nitroimidazole derivatives (nitroimidazoles and especially chloronitroimidazoles can be used as radiosensitizers of hypoxic cells; e.g. Widel et al., 1987), we have determined the crystal structures of two closely related compounds, viz. 5-chloro-1,2-dimethyl4-nitro-1 $H$-imidazole, (I), and 2-chloro-1-methyl-4-nitro- $1 H$ imidazole, (II). In both these compounds, halogen bonds of the $\mathrm{C}-\mathrm{Cl} \cdots \mathrm{O}_{\text {nitro }}$ type are the driving force of the supramolecular architecture.

In (I), the imidazole ring is planar, with a maximum deviation of 0.037 (6) $\AA$, and the closest substituent atoms (i.e. except for the $\mathrm{O}$ atoms) are almost coplanar with the ring [the maximum deviation from the plane, for atom $\mathrm{C} 11$, is 0.059 (2) $\AA$ ]. The nitro group is twisted by $6.97(7)^{\circ}$ with respect to the imidazole ring (Fig. 1). The molecule of (II) occupies a special position; it lies on a mirror plane and therefore is perfectly planar (Fig. 2). There are no traces of disorder or strangely shaped displacement ellipsoids, which might suggest the statistical nature of this mirror plane. The

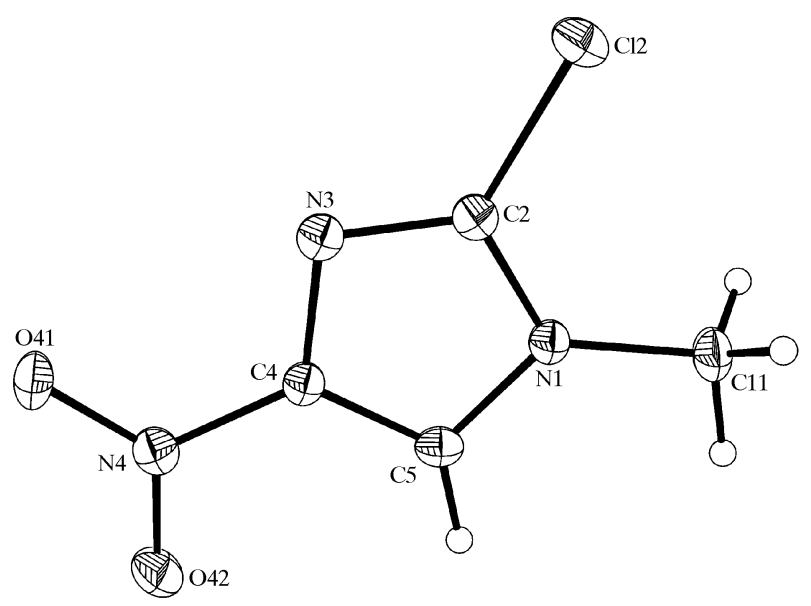

Figure 2

An anisotropic displacement ellipsoid representation of the molecule of (II), together with the atom-labelling scheme (Siemens, 1989). The ellipsoids are drawn at the $50 \%$ probability level and $\mathrm{H}$ atoms are depicted as spheres with arbitrary radii. same is true at room temperature, so it seems that in this temperature range there is no phase transition (of orderdisorder nature). The molecular dimensions are close to typical, with a notable influence of the type of substituents on the intramolecular $\mathrm{N} 1-\mathrm{C} 2-\mathrm{N} 3$ angles (Table 1$)$. The typical asymmetry of the $\mathrm{C}-\mathrm{N}-\mathrm{O}$ angles can also be observed here (cf. Kubicki, 2005).

In both structures, $\mathrm{C}-\mathrm{Cl} \cdots \mathrm{O}$ halogen bonds are the most important factor in the crystal packing. Noticeably, in neither of the structures does the imidazole $\mathrm{N}$ atom take part in the halogen bonding. This is in agreement with our observation (in high-resolution studies of the crystal structure of 1-phenyl-4nitroimidazole) that the electron density of the lone pairs is higher at the $\mathrm{O}$ atoms than at the imidazole $\mathrm{N}$ atom (Kubicki et al., 2002).

The types of interaction are different in both cases. For a description of the networks created by intermolecular interactions, it will be useful to apply the graph-set notation (Etter et al., 1990; Bernstein et al., 1995). We will follow Bryant et al. (1998) and regard the $\mathrm{Cl}$. . O interactions as pseudo-hydrogen bonds, with $\mathrm{Cl}$ as a donor and $\mathrm{O}$ as an acceptor. In (I), there is one very short and linear interaction of the cis type (Fig. 3 and Table 2). It is actually one of the shortest interactions of this type found in the Cambridge Structural Database (CSD; Allen, 2002). This interaction should be classified as belonging to type (iii) of those listed earlier. These halogen bonds connect the molecules into infinite chains along the [010] direction. The motif created by these interactions can be described as $C_{1}^{1}(5)$.

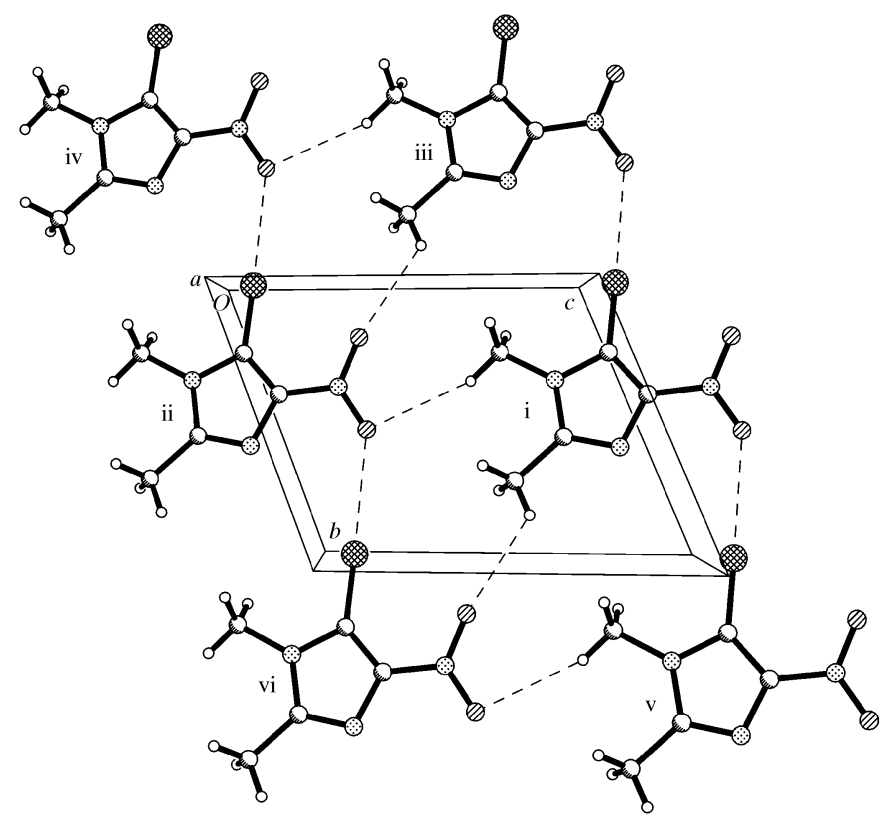

Figure 3

The layer created by halogen and weak hydrogen bonds in (I) (Siemens, 1989), as seen along the $a$ direction. Intermolecular interactions are depicted as dashed lines. [Symmetry codes: (i) $x, y, z$; (ii) $x, y, z-1$; (iii) $x$, $y-1, z$; (iv) $x, y-1, z-1$; (v) $x, y+1, z$; (vi) $x, y+1, z-1$.] 
In (II), the interaction is of another kind. The $\mathrm{C}-\mathrm{Cl}$ bond approaches two $\mathrm{O}$ atoms at moderate distances (Fig. 4 and Table 2), and both approaches are of cis type, because these two $\mathrm{O}$ atoms are from two different molecules. Therefore, it belongs - in principle - to type (iii), but the bifurcated nature of this contact allows the creation of a subtype, (iiia). In the CSD, we have found 69 hits with this motif. These halogen bonds connect molecules into two-dimensional layers in the $a b$ plane (on a mirror plane of symmetry; Fig. 4). This structure is much more complicated than that in (I). There are first-rank (i.e. built of only one type of interactions) chains, viz. $C_{1}^{1}(6)$ parallel to $a$ and $C_{1}^{1}(6)$ parallel to $c$. These chains interweave and produce second-rank (built of two different interactions) motifs, e.g. $C_{2}^{2}(8)$ chains along $a$ and closed structures of the $R_{3}^{4}(16)$ type.

The halogen-bonded arrays are further expanded by means of weak $\mathrm{C}-\mathrm{H}$. . O interactions (Table 2). In (I), these bonds connect neighbouring chains into layers, closing consecutive $R_{2}^{3}(12)$ rings (Fig. 3). In this structure, additional $\pi-\pi$ interactions between the imidazole rings connected by a centre of symmetry create the bilayers. The distance between the centres of the rings (which are parallel by symmetry) is 3.314 (2) $\AA$, and taking the offset into account the distance between the planes is $3.27 \AA$. In (II), the weak hydrogen bonds additionally strengthen the halogen-bonded layers, creating $R_{2}^{2}(8)$ ring motifs. The mirror planes occupied by these layers are $b / 2$ apart $(3.07 \AA)$, but the layers are shifted in such a way that the ring planes do not overlap at all.

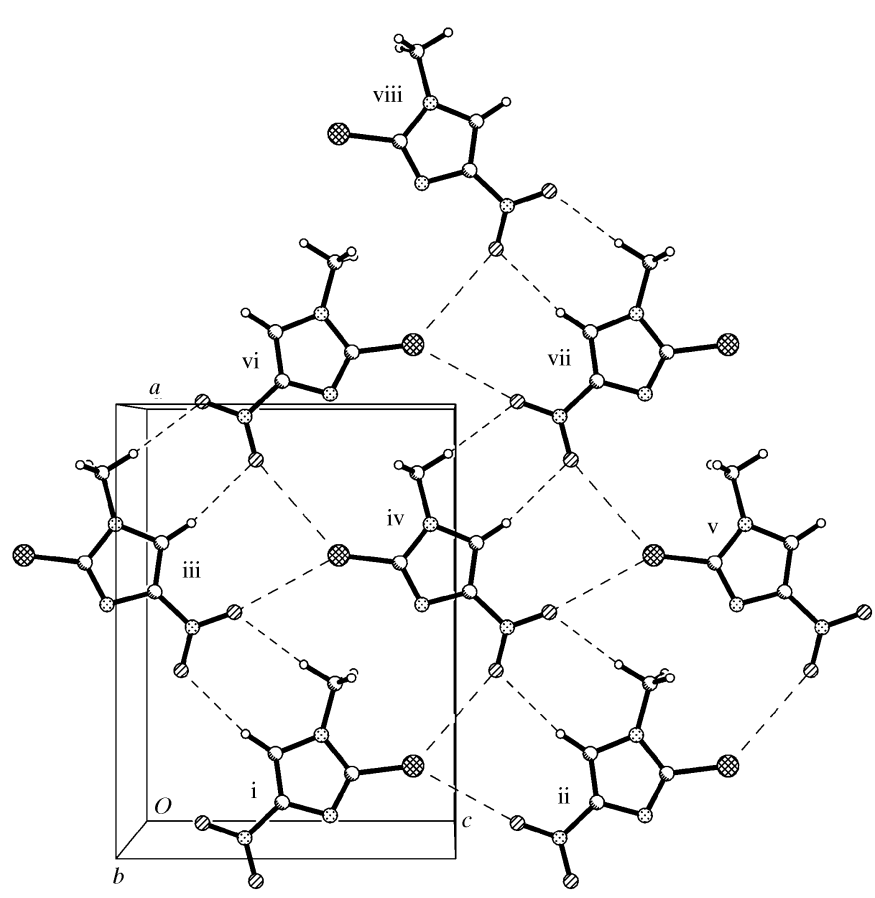

Figure 4

The layer created by halogen and weak hydrogen bonds in (II) (Siemens, 1989), as seen along the $b$ direction. Intermolecular interactions are depicted as dashed lines. [Symmetry codes: (i) $x, y, z$; (ii) $x, y, z+1$; (iii) $x+\frac{1}{2}, y,-z+\frac{1}{2}$; (iv) $x+\frac{1}{2}, y,-z+\frac{3}{2}$; (v) $x+\frac{1}{2}, y,-z+\frac{5}{2}$; (vi) $x+1, y, z$; (vii) $x+1, y, z+1$; (viii) $x+\frac{3}{2}, y,-z+\frac{3}{2}$.]

\section{Experimental}

The investigated compounds were synthesized from the corresponding dinitro compounds in high yield according to a previously described procedure (Suwiński et al., 1982).

\section{Compound (I)}

\section{Crystal data}

$\mathrm{C}_{5} \mathrm{H}_{6} \mathrm{ClN}_{3} \mathrm{O}_{2}$

$M_{r}=175.58$

Triclinic, $P \overline{1}$

$a=6.8119$ (10) ^

$b=7.0301(12) \AA$

$c=8.5403(13) \AA$

$\alpha=66.631(16)^{\circ}$

$\beta=80.204(13)^{\circ}$

\section{Data collection}

Kuma KM-4 CCD four-circle diffractometer

Absorption correction: multi-scan (SORTAV; Blessing, 1989)

$T_{\min }=0.895, T_{\max }=0.944$

\section{Refinement}

$R\left[F^{2}>2 \sigma\left(F^{2}\right)\right]=0.025$

$w R\left(F^{2}\right)=0.066$

$S=1.08$

1767 reflections

$\gamma=71.305(14)^{\circ}$

$V=355.19(10) \AA^{3}$

$Z=2$

Mo $K \alpha$ radiation

$\mu=0.49 \mathrm{~mm}^{-1}$

$T=100(1) \mathrm{K}$

$0.15 \times 0.1 \times 0.1 \mathrm{~mm}$

3402 measured reflections 1767 independent reflections 1565 reflections with $I>2 \sigma(I)$ $R_{\text {int }}=0.040$

124 parameters All $\mathrm{H}$-atom parameters refined

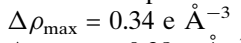
$\Delta \rho_{\min }=-0.38{\mathrm{e} \AA^{-3}}^{-3}$

\section{Compound (II)}

Crystal data

$\mathrm{C}_{4} \mathrm{H}_{4} \mathrm{ClN}_{3} \mathrm{O}_{2}$

$M_{r}=161.55$

Orthorhombic, Pnma

$a=11.6550$ (9) $\AA$

$b=6.1372(5) \AA$

$c=8.6994$ (6) §

Data collection

Kuma KM-4 CCD four-circle diffractometer

Absorption correction: multi-scan (SORTAV; Blessing, 1989) $T_{\min }=0.940, T_{\max }=0.944$

Refinement

$R\left[F^{2}>2 \sigma\left(F^{2}\right)\right]=0.030$

$w R\left(F^{2}\right)=0.065$

$S=1.01$

922 reflections
$V=622.26(8) \AA^{3}$

$Z=4$

Mo $K \alpha$ radiation

$\mu=0.55 \mathrm{~mm}^{-1}$

$T=100(1) \mathrm{K}$

$0.2 \times 0.15 \times 0.1 \mathrm{~mm}$

6383 measured reflections 922 independent reflections 696 reflections with $I>2 \sigma(I)$ $R_{\text {int }}=0.034$

71 parameters

All $\mathrm{H}$-atom parameters refined $\Delta \rho_{\max }=0.26 \mathrm{e}^{-3}$

$\Delta \rho_{\min }=-0.31 \mathrm{e}^{-3}$

Table 1

Selected geometrical parameters $\left(\AA{ }^{\circ}\right)$.

\begin{tabular}{lcl}
\hline & (I) & (II) \\
\hline $\mathrm{C} 2-\mathrm{N} 1-\mathrm{C} 5$ & $106.8(1)$ & $106.4(2)$ \\
$\mathrm{C} 2-\mathrm{N} 3-\mathrm{C} 4$ & $104.6(1)$ & $102.7(2)$ \\
$\mathrm{N} 3-\mathrm{C} 2-\mathrm{N} 1$ & $111.91(9)$ & $113.75(18)$ \\
$\mathrm{C} 4-\mathrm{N} 4-\mathrm{O} 41$ & $118.9(1)$ & $119.0(2)$ \\
$\mathrm{C} 4-\mathrm{N} 4-\mathrm{O} 42$ & $117.9(1)$ & $117.0(2)$ \\
$\mathrm{N} 3-\mathrm{C} 4-\mathrm{N} 4$ & $122.0(1)$ & $121.5(2)$ \\
$\mathrm{C} 5-\mathrm{C} 4-\mathrm{N} 4$ & $126.9(2)$ & $125.6(2)$ \\
& & 0 \\
$\mathrm{~N} 3-\mathrm{C} 4-\mathrm{N} 4-\mathrm{O} 41$ & $6.9(1)$ & 180 \\
$\mathrm{~N} 3-\mathrm{C} 4-\mathrm{N} 4-\mathrm{O} 42$ & $-173.3(1)$ & 0 \\
Imidazole/NO & $6.97(7)$ & \\
\hline
\end{tabular}


Table 2

Halogen- and hydrogen-bond data $\left(\AA,^{\circ}\right)$.

\begin{tabular}{lllll}
\hline $\mathrm{C}-\mathrm{Cl} \cdots \mathrm{O}$ & $\mathrm{C}-\mathrm{Cl}$ & $\mathrm{Cl} \cdots \mathrm{O}$ & $\mathrm{C}-\mathrm{Cl} \cdots \mathrm{O}$ & $\mathrm{C}-\mathrm{N}-\mathrm{O} \cdots \mathrm{C}$ \\
\hline$(\mathrm{I})$ & & & & \\
$\mathrm{C} 5-\mathrm{Cl} 5 \cdots \mathrm{O} 41^{\mathrm{i}}$ & $1.690(1)$ & $2.899(1)$ & $175.90(4)$ & $-5.4(1)$ \\
& & & & \\
$(\mathrm{II})$ & $1.701(2)$ & $3.285(2)$ & $144.3(1)$ & 0 \\
$\mathrm{C} 2-\mathrm{Cl} 2 \cdots \mathrm{O} 42^{\mathrm{ii}}$ & $1.701(2)$ & $3.498(2)$ & $138.0(1)$ & 0 \\
$\mathrm{C} 2-\mathrm{Cl} 2 \cdots \mathrm{O} 41^{\mathrm{iii}}$ & & &
\end{tabular}

\begin{tabular}{lllll}
\hline$D-\mathrm{H} \cdots A$ & $D-\mathrm{H}$ & $\mathrm{H} \cdots A$ & $D \cdots A$ & $D-\mathrm{H} \cdots A$ \\
\hline (I) & & & & \\
$\mathrm{C} 11-\mathrm{H} 11 C \cdots \mathrm{O} 41^{\text {iv }}$ & $0.94(2)$ & $2.66(2)$ & $3.545(2)$ & $157(2)$ \\
$\mathrm{C} 21-\mathrm{H} 21 A \cdots \mathrm{O} 42^{\mathrm{v}}$ & $0.94(2)$ & $2.67(2)$ & $3.318(2)$ & $126(1)$ \\
$(\mathrm{II})$ & & & & \\
$\mathrm{C} 11-\mathrm{H} 11 A \cdots \mathrm{O} 42^{\text {vi }}$ & $1.01(2)$ & $2.40(2)$ & $3.405(1)$ & $175(2)$ \\
$\mathrm{C} 5-\mathrm{H} 5 \cdots \mathrm{O} 41^{\text {vii }}$ & $0.99(3)$ & $2.50(3)$ & $3.475(2)$ & $169(3)$ \\
\hline
\end{tabular}

Symmetry codes: (i) $x, y-1, z$; (ii) $x, y, z+1$; (iii) $x+\frac{1}{2}, y,-z+\frac{3}{2}$; (iv) $x, y, z-1$; (v) $x, y+1, z+1$; (vi) $x+\frac{1}{2}, y,-z+\frac{3}{2}$; (vii) $x+\frac{1}{2}, y,-z+\frac{1}{2}$; (ix) $-x+1, y+\frac{1}{2},-z+\frac{3}{2}$; (x) $x,-y+\frac{3}{2}, z+\frac{1}{2}$; (xi) $x, y-1, z$.

$\mathrm{H}$ atoms were freely refined $[\mathrm{C}-\mathrm{H}=0.93$ (2)-1.005 (18) $\AA$ in (I) and 0.90 (2)-1.01 (3) $\AA$ in (II)].

For both compounds, data collection: CrysAlis CCD (Oxford Diffraction, 2002); cell refinement: CrysAlis CCD; data reduction: CrysAlis RED (Oxford Diffraction, 2002); program(s) used to solve structure: SHELXS97 (Sheldrick, 1997); program(s) used to refine structure: SHELXL97 (Sheldrick, 1997); molecular graphics: Stereochemical Workstation Operation Manual (Siemens, 1989); software used to prepare material for publication: SHELXL97.

Supplementary data for this paper are available from the IUCr electronic archives (Reference: SK3142). Services for accessing these data are described at the back of the journal.

\section{References}

Allen, F. H. (2002). Acta Cryst. B58, 380-388.

Allen, F. H., Lommerse, J. P. M., Hoy, V. J., Howard, J. A. K. \& Desiraju, G. R. (1997). Acta Cryst. B53, 1006-1016.

Bent, H. A. (1968). Chem. Rev. 68, 587-648.
Bernstein, J., Davis, R. E., Shimoni, L. \& Chang, N.-L. (1995). Angew. Chem. Int. Ed. Engl. 34, 1555-1573.

Bianchi, R., Forni, A. \& Pilati, T. (2003). Chem. Eur. J. 9, 1631-1638.

Bianchi, R., Forni, A. \& Pilati, T. (2004). Acta Cryst. B60, 559-568.

Blessing, R. H. (1989). J. Appl. Cryst. 22, 396-397.

Bryant, R., James, S. C., Norman, N. C. \& Orpen, A. G. (1998). Acta Cryst. C54, 1113-1115.

Dahl, T. \& Hassel, O. (1970). Acta Chem. Scand. 24, 377-382.

Desiraju, G. R. (1995). Angew. Chem. Int. Ed. Engl. 34, 2311-2327.

Desiraju, G. R., Pedireddi, V. R., Sarma, J. A. R. P. \& Zacharias, D. E. (1993). Acta Chim. Hung. 130, 451-465.

Dumas, J. M., Gomel, L. \& Guerin, M. (1983). The Chemistry of Functional Groups, Suppl. D, edited by S. Patai \& Z. Rappaport, pp. 985-1020. New York: Wiley.

Etter, M. C., MacDonald, J. C. \& Bernstein, J. (1990). Acta Cryst. B46, 256-262.

George, S., Nangia, A., Lam, C.-K., Mak, T. C. W. \& Nicoud, J.-F. (2004). Chem. Commun. pp. 1202-1203.

Hassel, O. (1970). Science, 170, 497-502.

Hassel, O. \& Rømming, C. (1962). Q. Rev. Chem. Soc. 16, 1-13.

Imakubo, T., Maruyama, T., Sawa, H. \& Kobayashi, K. (1998). Chem. Commun. pp. 2021-2022.

Kubicki, M. (2004). Acta Cryst. C60, o341-o343.

Kubicki, M. (2005). J. Mol. Struct. 743, 209-215.

Kubicki, M., Borowiak, T., Dutkiewicz, G., Souhassou, M., Jelsch, C. \& Lecomte, C. (2002). J. Phys. Chem. B, 106, 3706-3714.

Legon, A. C. (1998). Chem. Eur. J. 4, 1890-1897.

Legon, A. C. (1999). Angew. Chem. Int. Ed. 38, 2687-2714.

Lommerse, J. P. M., Stone, A. J., Taylor, R. \& Allen, F. H. (1996). J. Am. Chem. Soc. 118, 3108-3116.

Messina, M. T., Metrangolo, P., Panzeri, W., Pilati, T. \& Resnati, G. (2001). Tetrahedron, 57, 8543-8550.

Metrangolo, P., Neukirch, H., Pilati, T. \& Resnati, G. (2005). Acc. Chem. Res. 38, 386-395.

Oxford Diffraction (2002). CrysAlis CCD and CrysAlis RED. Versions 1.169. Oxford Diffraction, Wrocław, Poland.

Reddy, D. S., Craig, D. C., Rae, A. D. \& Desiraju, G. R. (1993). J. Chem. Soc. Chem. Commun. pp. 1737-1739.

Reddy, D. S., Panneerselvam, K., Pilati, T. \& Desiraju, G. R. (1993). J. Chem. Soc. Chem. Commun. pp. 661-662.

Sheldrick, G. M. (1997). SHELXS97 and SHELXL97. University of Göttingen, Germany.

Siemens (1989). Stereochemical Workstation Operation Manual. Release 3.4. Siemens Analytical X-ray Instruments Inc., Madison, Wisconsin, USA.

Suwiński, J., Salwińska, E., Watras, J. \& Widel, M. (1982). Pol. J. Chem. 56, $1261-1272$.

Valerio, G., Raos, G., Meille, S. V., Metrangolo, P. \& Resnati, G. (2000). J. Phys. Chem. A, 104, 1617-1620.

Wash, P. L., Ma, S., Obst, U. \& Rebek, J. Jr (1999). J. Am. Chem. Soc. 121, 7973-7974.

Widel, M., Watras, J., Suwiński, J. \& Salwińska, E. (1987). Neoplasma, 34, 241251. 